\title{
Differential Diagnosis of Small Cell Carcinoma of the Ovary or Ovarian Metastases of Small Cell Carcinoma of the Lung: A Case Report and Review of the Literature
}

\author{
Ester Oneda ${ }^{a}$ Fausto Zorzi ${ }^{b}$ Antonio Gorio ${ }^{c}$ Federico Quaglia ${ }^{c}$ \\ Chiara Abeni $^{a}$ Luigina Rota ${ }^{a}$ Alberto Zaniboni ${ }^{a}$ \\ aDepartment of Clinical Oncology, Fondazione Poliambulanza, Brescia, Italy; \\ bepartment of Pathology, Fondazione Poliambulanza, Brescia, Italy; \\ 'Department of Gynaecology, Fondazione Poliambulanza, Brescia, Italy
}

\section{Keywords}

Small cell carcinoma of the ovary $\cdot$ Small cell lung cancer $\cdot$ Small cell

\begin{abstract}
Small cell tumors arise from the neuroendocrine cell system and they are most frequently found in the lung (SCLC). Small cell tumor could occasionally arise in other body sites, such as the cervix, prostate, gastrointestinal tract, and very rarely from other sites. Metastatic SCLC patients present with metastatic disease in $80 \%$ of cases, and the metastases typically are reported in brain, liver, lung, and bone; they rarely could be found in the ovary. Differently, primitive small cell carcinoma of the ovary of pulmonary type is a rare and highly aggressive tumor arising from the ovarian cells; no suitable treatment strategy has been established yet. In this paper, we talk about a 72-year-old woman who presented with abdominal bleeding and a large mass in her pelvic region. A primary ovarian carcinoma was suspected, and she underwent hysterectomy with laparoscopic surgery and bilateral oophorectomy, lymph node resection, omentectomy, complementary appendix and sigmoid resection. The postoperative pathologic diagnosis was a differential diagnosis between small cell ovarian carcinoma of the pulmonary type and metastasis of SCLC.




\section{Case Reports in Oncology}

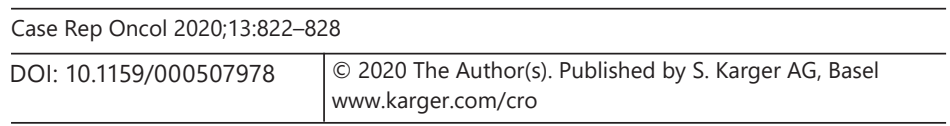

Oneda et al.: Differential Diagnosis of SCO or Ovarian Metastases of SCLC

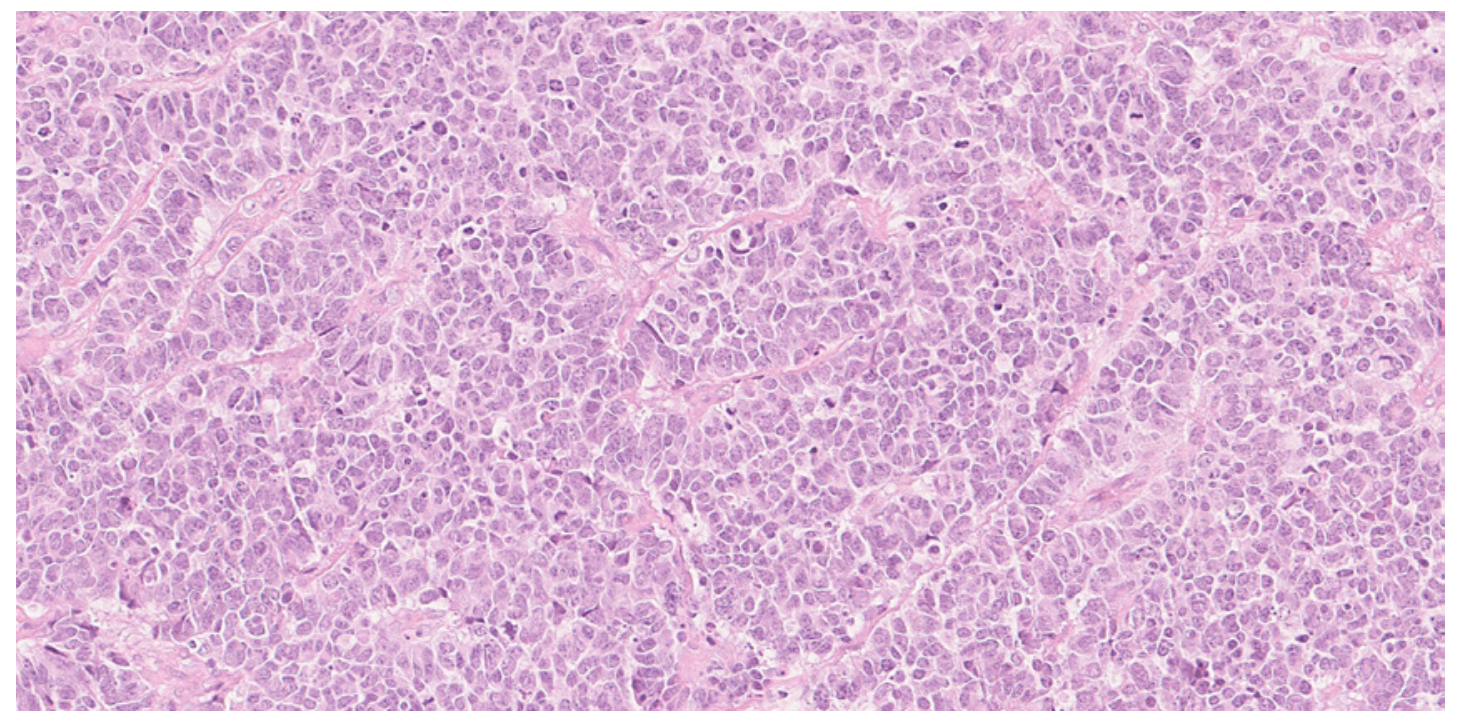

Fig. 1. The tumor consists of multi-anastomized cords of polygonal cells with moderately polymorphic nuclei with some mitoses (H\&E stain, $\times 20$ magnification).

\section{Introduction}

Most frequently, small cell tumors arise from the lung (SCLC), and metastases occur early in the course of the disease, often at the time of diagnosis, with common spread to the mediastinal lymph nodes, liver, bones, adrenal glands, and brain [1]. However, its metastasis to the ovary is a sporadic occurrence, and an extensive literature search revealed only few of such documented cases [2,3]. Small cell carcinoma of the ovary (SCO) is a rare condition, accounting for approximately $1 \%$ of all ovarian neoplasms [4]. There are two types of SCO: the hypercalcemic type (SCOHT) and the pulmonary type (SCOPT) based on the pathologic findings and immunostaining profile of each tumor. The clinical features of SCOHT and SCOPT are different: SCOHT typically affects younger women (mean age, 22 years) than SCOPT (mean age, 51 years). Both are highly aggressive malignancies, but while SCOHT is resistant to chemotherapy and radiotherapy, progressing rapidly, SCOPT is sensitive to chemotherapy [2]. In order to their rarity, there are no specific treatment guidelines, although the prognosis is known to be poorer than common epithelial ovarian carcinomas. The few cases (less than 50 cases of SCOPT in the literature) are reported as case reports [5]. Here we present the case of a woman who presented an SCO that is a differential diagnosis between these two histologies.

\section{Case Presentation}

A 72-year-old woman (gravida 1, para 1) presented at our hospital with vaginal bleeding. She had a family history of paternal gastric cancer and maternal breast cancer. Gynecological examination showed a $6 \times 4 \mathrm{~cm}$ mass in her left pelvic region. Abdominal magnetic resonance imaging identified a unilateral left ovarian mass. The tumor, approximately $6 \times 5 \mathrm{~cm}$ in diameter, revealed a solid pattern and was vascularized, similar to ovarian carcinoma. Computed tomography (CT) revealed some millimetric non-calcific nodules in both lungs, some lymph node metastasis in the pelvis, ascites, and abdominal and pelvic nodules. She underwent simple laparoscopic hysterectomy with bilateral oophorectomy, lymph node resection, omentectomy, complementary appendectomy, and sigmoid resection with end-to- 


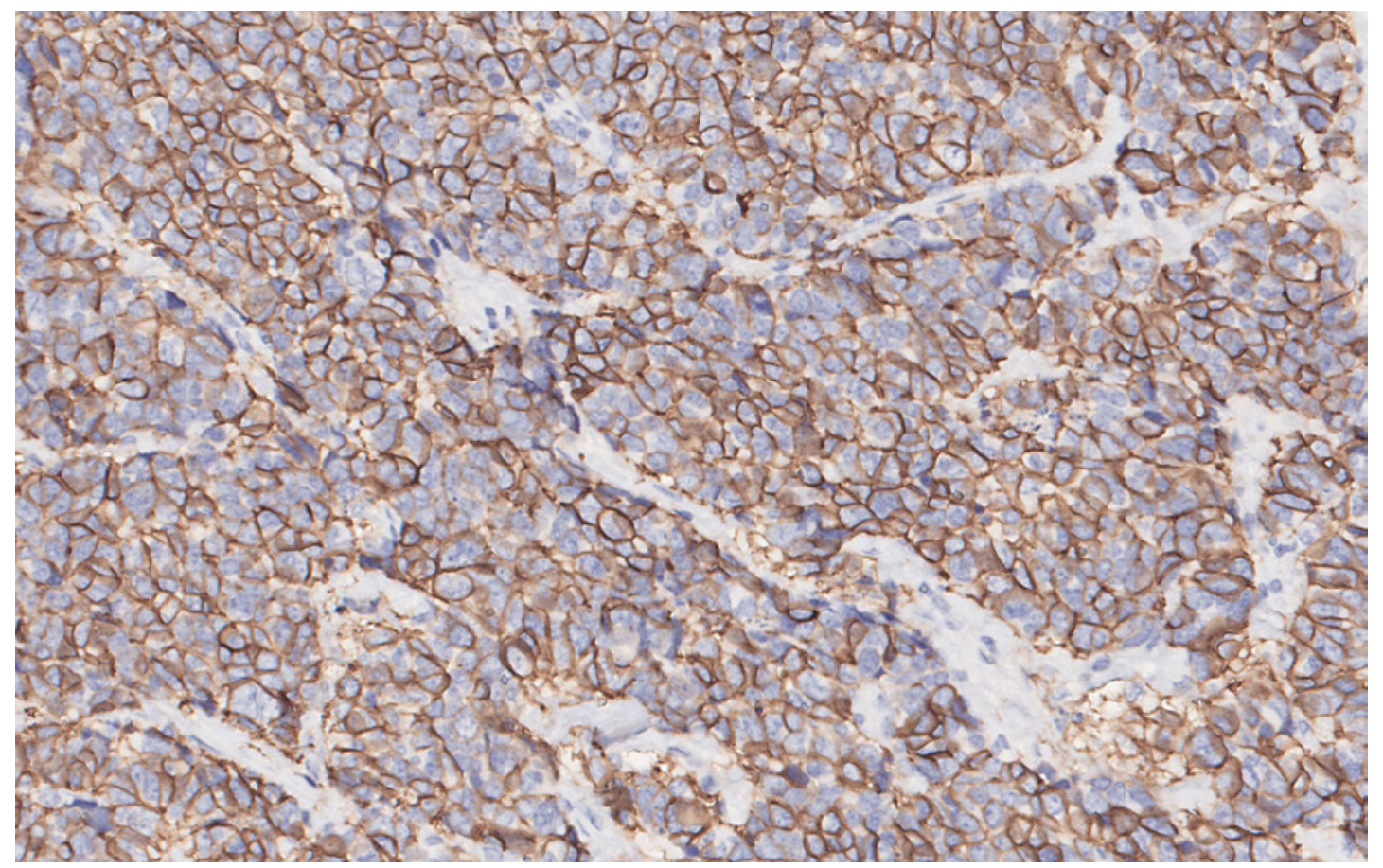

Fig. 2. Neoplastic cells show a multifocal "dot like" cytoplasmic positivity to chromogranin A ( $\times 20$ magnification).

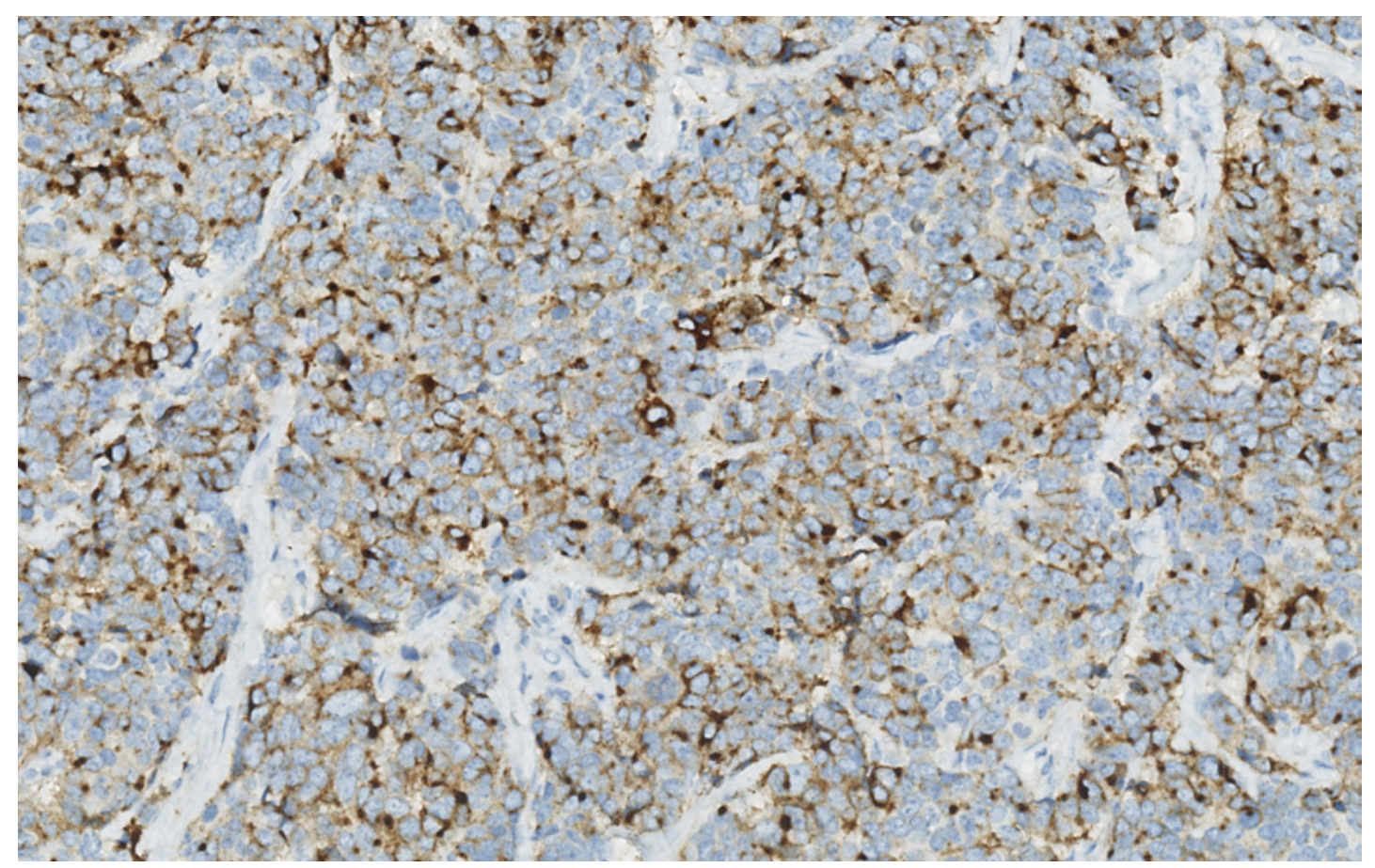

Fig. 3. Neoplastic cells show diffuse nuclear positivity to TTF-1 ( $\times 20$ magnification). 


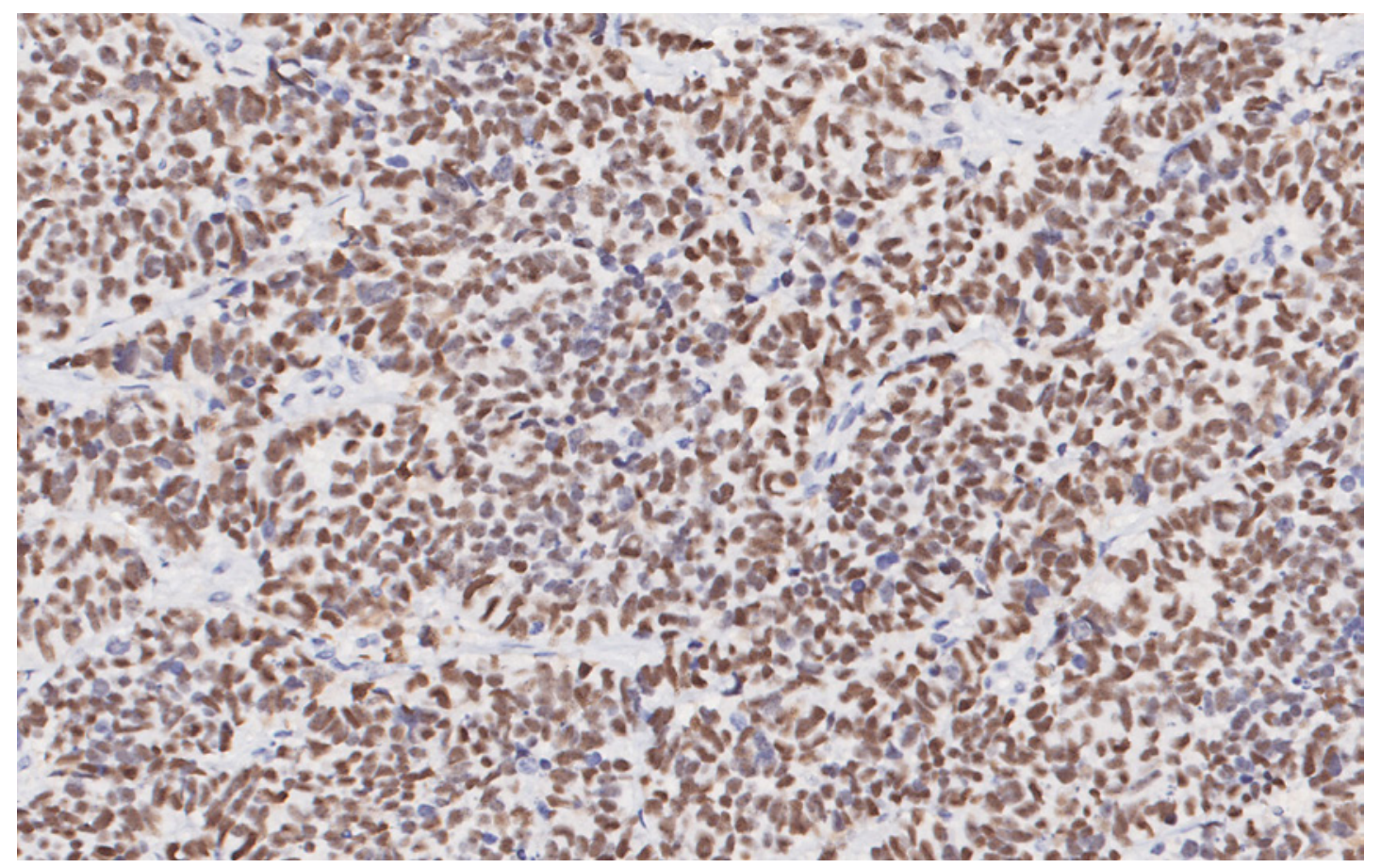

Fig. 4. Neoplastic cells marked by neuroendocrine marker synaptophysin (×20 magnification).

end anastomosis. Histopathologic examination revealed small round cells with scant cytoplasm, arranged in diffuse or insular patterns with slightly spindled, hyperchromatic nuclei in both ovaries, in the omentum, and in 14 lymph nodes close to the bladder and 2 left paraaortic lymph nodes; the capsule of the left ovary was broken. The FIGO stage was IIIC. These findings had similar morphology to those of SCLC. Immunohistochemistry staining for TTF1, c-Kit, EMA, CD56, chromogranin A, synaptophysin, and p16 and p53 (100\% cells) were positive (Fig. 1, Fig. 2, Fig. 3, Fig. 4), while WT1, ER, GATA-3, and CK20 were negative. The cells were undifferentiated with a proliferative index (Ki67) of 50\%. The differential pathologic diagnosis was SCOPT or metastases of SCLC; the absence of positivity for CK20 [3] and the presence of cancer cells in both ovaries could indicate a pulmonary origin, but we had only micronodules in the lung at CT scan without a primary mass. Patient's serum calcium level was $8.9 \mathrm{mg} / \mathrm{dL}$, CA125 level $55 \mathrm{U} / \mathrm{mL}$, and neuron specific enolase (NSE) level $17.9 \mathrm{ng} / \mathrm{mL}$. In consideration of the histology, the age of the patient, her cardiologic history, and her will to avoid alopecia, she underwent 4 cycles of chemotherapy with carboplatin AUC 5. After the ending of chemotherapy, CT scan showed a volumetric reduction of lung nodules and absence of abdominal mass or liquid. Her serum CA125 level had dropped to $14 \mathrm{U} / \mathrm{mL}$, and NSE level was $14.1 \mathrm{ng} / \mathrm{mL}$.

\section{Discussion}

SCO is a very rare tumor, and SCOHT is the most frequent subtype, which generally affects young women. High level of serum calcium is present in approximately two thirds of cases [6]. Furthermore, it seems to be related with inactivating germline and somatic mutations of the SMARCA4 gene [7]. We excluded this type due to our patient's age and to 
Table 1. Immunohistochemistry for the differential diagnosis of small cell cancers of the lung and of the ovary

\begin{tabular}{|c|c|c|c|c|c|}
\hline & Median age & Small cells & Immunochemistry & Hypercalcemia & Chemosensitivity \\
\hline SCLC & $>50$ years & + & $\begin{array}{l}\text { TTF-1 + } \\
\text { Synaptophysin + } \\
\text { Chromogranin A + } \\
\text { CD } 56+ \\
\text { CK } 20 \text { - } \\
\text { P53 + }\end{array}$ & + & + \\
\hline SCOHT & 24 years & + & $\begin{array}{l}\text { TTF-1 - } \\
\text { Synaptophysin + } \\
\text { Chromogranin A + } \\
\text { CD 56 + } \\
\text { CK } 20+ \\
\text { P53 + }\end{array}$ & + & $+/-$ \\
\hline SCOPT & $>50$ years & + & $\begin{array}{l}\text { TTF-1 - } \\
\text { Synaptophysin + } \\
\text { Chromogranin A + } \\
\text { CD } 56+ \\
\text { CK } 20+ \\
\text { P53 + }\end{array}$ & - & + \\
\hline
\end{tabular}

SCLC, small cell lung cancer; SCOHT, small cell carcinoma of the ovary of hypercalcemic type; SCOPT, small cell carcinoma of the ovary of pulmonary type.

the normal level of serum calcium, but we performed neither genetic analysis in our patient nor immunostaining for SMARCA4. Instead, the lesions of SCOPT affect middleaged women and are chemotherapy sensitive, but they have high disease progression risk soon after completing the treatment [8]. SCO are immune-positive for neuroendocrine markers, similar to small cell carcinoma of other organs [9]. Metastases of SCOPT can be found in the omentum, lymph nodes, peritoneum, intestine, liver, lungs, and breast. The recurrence rate, even in patients with disease limited to the ovaries (stage Ia and Ib), was high, approximately $60 \%$ of patients [10]. Most patients are treated with etoposide and cisplatin, the same treatment used for SCLC. Carboplatin and cisplatin have the same efficacy, but carboplatin has the advantage of requiring lower fluid intake and less toxicity. However, no randomized trial compared the two drugs [11]. On the other hand, SCLC metastases are often found in lymph nodes and distant organs at diagnosis, but the reported frequency of ovarian metastases from primary lung carcinoma (including SCLC) is approximately $0.4 \%$ [12]. Moreover, the patient was a never-smoker, and smoking is the most influencing risk factor for SCLC [1]. Differentiating between ovarian metastasis of SCLC and primary SCO is challenging as both tumors present similar histological and immunohistochemical findings (they are summarized in Table 1). Typically, TTF-1, synaptophysin, and chromogranin A test positive for small cell carcinoma of any organ other than the lung. Although the standard treatment for SCLC has been established, a treatment protocol for primary SCO has not yet been defined yet [12]. Ultrasound was negative and positron emission tomography (PET) is not indicated for nodules of less than $8 \mathrm{~mm}$ in diameter [13] due to the significant risk of false-negative findings; so we could not perform PET in our patients to discriminate if the millimetric lung lesions were pathologic or not, due to their volume. 


\section{Conclusion}

In our patient, we did not know whether the primary tumor is of the ovary or of the lung. We decided to give chemotherapy with carboplatin, instead of carboplatin plus etoposide, due to the patient's age and performance status. It was effective: the patient showed no evidence of recurrence at the revaluation at 6 and 12 months from the start of chemotherapy. In the case of disease progression, our patient will benefit from local treatment like surgery or radiotherapy, relative to the site of recurrence, or in the case of systemic spread, a new combined chemotherapy regime or a reintroduction of the prime treatment in consideration of the relapsed time. In this case we could perform NGS in order to exclude a SCOHT or eventually any targetable mutation. We need clinical multicenter trials to provide evidence on the use of multiple chemotherapy and radiotherapy regimens in this setting of patients to develop standardized therapeutic strategy.

\section{Statement of Ethics}

The description of cases is retrospective, and the person involved maintained completely anonymous. The patient in this paper has given written informed consent to publication of her case details and images.

\section{Conflict of Interest Statement}

The authors have no conflicts of interest.

\section{Funding Sources}

Authors have no funders.

\section{Author Contributions}

Ester Oneda: the author has dealt with the collection of data, selection of case report and with the drafting of the article. Fausto Zorzi: the author has dealt with the revision of the article. Antonio Gorio: the author has dealt with the collection of data and the selection of case report. Federico Quaglia: the author has dealt with the revision of the article and with the approval of the final version. Chiara Abeni: the author has dealt with the collection of data and the selection of case report. Luigina Rota: the author has dealt with the collection of data and the selection of case report. Alberto Zaniboni: the author has dealt with the revision of the article and with the approval of the final version.

\section{References}

1 Cascone T, Gold KA, Glisson BS. Small cell carcinoma of the lung. In Kantarjian H, Wolff R, eds. The MD Anderson Manual of Medical Oncology. 3rd ed. NY: McGraw-Hill Education, 2016; pp. 323-42.

2 Münstedt K, Estel R, Dreyer T, Kurata A, Benz A. Small Cell Ovarian Carcinomas - Characterisation of Two Rare Tumor Entities. Geburtshilfe Frauenheilkd. 2013 Jul;73(7):698-704.

3 Malviya VK, Bansal M, Chahinian P, Deppe G, Lauersen N, Gordon RE. Small cell anaplastic lung cancer presenting as an ovarian metastasis. Int J Gynaecol Obstet. 1982;20(6):487-93. 
4 Dickersin GR, Kline IW, Scully RE. Small cell carcinoma of the ovary with hypercalcemia: a report of eleven cases. Cancer. 1982;49(1):188-97.

5 Yoshida Y, Kaneki E, Kijima M, Kodama K, Yamaguchi S, Yagi H, et al. Two types of small cell carcinoma of the ovary: two typical case reports. Gynecol Oncol Rep. 2018 Aug;25:125-30.

6 Gerday A, Marbaix E, Squifflet JL, Mazzeo F, Luyckx M. Small cell carcinoma of the ovary with hypercalcemia: case report and review of the literature. Clin J Obstet Gynecol. 2018;1:035-44.

7 David M, Okamoto A, Ray-Coquard I. Management of rare ovarian cancer histologies. J Clin Oncol. September 20, 2019;37(27):2406-15.

8 Eichhorn JH, Young RH, Scully RE. Primary ovarian small cell carcinoma of pulmonary type. A clinicopathologic, immunohistologic, and flow cytometric analysis of 11 cases. Am J Surg Pathol. 1992;16(10):926-38.

9 Rund CR, Fischer EG. Perinuclear dot-like cytokeratin 20 staining in small cell neuroendocrine carcinoma of the ovary (pulmonary-type). Appl Immunohistochem Mol Morphol. 2006;14(2):244-8

10 Kurman RJ, Carcangiu ML, Herrington CS, Young RH. WHO Classification of Tumor of Female Reproductive Organs, 4th ed. Lyon, France: International Agency for Research on Cancer Press, 2014; pp. 70-1.

11 Reed NS, Pautier P, Åvall-Lundqvist E, Choi CH, du Bois A, Friedlander M, et al. Gynecologic Cancer InterGroup (GCIG) Consensus Review for Ovarian Small Cell Cancers. Int J Gynecol Cancer. 2014 Nov;24(9 Suppl 3):S30-4.

12 Irving JA, Young RH. Lung carcinoma metastatic to the ovary: a clinicopathologic study of 32 cases emphasizing their morphologic spectrum and problems in differential diagnosis. Am J Surg Pathol. 2005;29(8):9971006.

13 Patel VK, Naik SK, Naidich DP, Travis WD, Weingarten JA, Lazzaro R, et al. A practical algorithmic approach to the diagnosis and management of solitary pulmonary nodules: part 1: radiologic characteristics and imaging modalities. Chest. 2013 Mar;143(3):825-39. 